\title{
Role of ghrelin in small intestinal motility following pediatric intracerebral hemorrhage in mice
}

\author{
JIEYU ZAN ${ }^{1}$, LEI SONG ${ }^{1}$, JIEJIE WANG ${ }^{1}$, RONG ZOU ${ }^{1}$, FEI HONG ${ }^{1}$, \\ JINHUA ZHAO $^{1}$, YIJUN CHENG ${ }^{2}$ and MING XU ${ }^{1}$ \\ ${ }^{1}$ Department of Pediatrics, Nantong First People's Hospital, Nantong University School of Medicine, \\ Nantong, Jiangsu 226001; ${ }^{2}$ Department of Neurosurgery, Rui Jin Hospital, \\ Shanghai Jiao Tong University School of Medicine, Shanghai 200025, P.R. China
}

Received June 24, 2016; Accepted April 25, 2017

DOI: $10.3892 / \mathrm{mmr} .2017 .7468$

\begin{abstract}
Small intestinal motility (SIM) disorder is a common complication following pediatric intracerebral hemorrhage (ICH), leading to a poor prognosis in patients. Previous studies have shown that ghrelin is involved in SIM in various diseases; however, the role of ghrelin in pediatric ICH-induced SIM disorder remains to be elucidated. The present study was designed to investigate the association between ghrelin and SIM post-ICH, and to examine the effect of exogenous ghrelin administration on SIM in vivo. An ICH model was induced in mice by autologous blood infusion. Neurobehavioral deficits were evaluated using a Rotarod test, forelimb placing test, and corner turn test. Intestinal mucosal damage was examined using hematoxylin and eosin staining. SIM was measured using charcoal meal staining. An enzyme-linked immunosorbent assay was used to evaluate serum levels of ghrelin and nitric oxide (NO). Reverse transcription-quantitative polymerase chain reaction and western blot analyses were performed to determine the levels of inducible nitric oxide synthase (iNOS), neuronal nitric oxide synthase (nNOS) and endothelial nitric oxide synthase (eNOS) at the mRNA and protein levels. $N_{\omega}$-nitro-L-arginine methyl ester hydrochloride (L-NAME), L-arginine, atropine, phentolamine and propranolol were used to manipulate the putative pathways induced by ghrelin. Neurological dysfunction was observed post-ICH.
\end{abstract}

Correspondence to: Professor Ming Xu, Department of Pediatrics, Nantong First People's Hospital, Nantong University School of Medicine, 6 North Haierxiang Road, Nantong, Jiangsu 226001, P.R. China

E-mail: ntsyek@qq.com

Dr Yijun Cheng, Department of Neurosurgery, Rui Jin Hospital, Shanghai Jiao Tong University School of Medicine, 197 Rui Jin Er Road, Shanghai 200025, P.R. China

E-mail: jesny1988@163.com

Key words: ghrelin, intracerebral hemorrhage, small intestine motility, intestinal mucosa, inducible nitric oxide synthase, nitric oxide, cholinergic pathway
ICH caused damage to the intestinal mucosa and delayed SIM. Serum levels of ghrelin increased between $3 \mathrm{~h}$ and 3 days, peaking at $12 \mathrm{~h}$, and showed a significant negative correlation with SIM post-ICH. Ghrelin administration dose-dependently attenuated ICH-induced SIM disorder. Ghrelin also decreased NO levels by downregulating the mRNA and protein expression levels of iNOS, but not those of nNOS or eNOS, post-ICH. Consistently, the effect was enhanced by L-NAME and weakened by L-arginine, respectively. The protective effect of ghrelin was eradicated by atropine, but not phentolamine or propranolol. These findings suggested that ghrelin ameliorated SIM disorder by downregulating iNOS/NO via the cholinergic pathway. Therefore, ghrelin may serve as a potential biomarker and useful target in ICH-induced SIM disorder.

\section{Introduction}

Pediatric stroke is a rare but serious event with high rates of mortality and morbidity, is among the top 10 causes of mortality and is as common as brain tumors in children $(1,2)$. The incidence of childhood stroke is estimated at 2.10-13.02 per 100,000 individuals and intracerebral hemorrhage (ICH) accounts for almost 50\% of all stroke cases (3-6). By contrast, ICH in adults only comprises $\sim 10-30 \%$ of cases (7). Pediatric ICH has a mortality rate of $\sim 25 \%$ and leads to significant disability in $42 \%$ of those who survive (8), which results in a significant burden on families and society.

Small intestinal motility (SIM) disorder presents primarily with early satiety, bloating, nausea, vomiting and loss of appetite (9). The motility disorder may result in the abnormal propulsion of intestinal content and nutrient malabsorption, leading to impaired intestinal mucosa and barrier function, deficient immunity, translocation of intestinal bacteria and endotoxins, and even systemic inflammatory response syndrome and multiple organ dysfunction syndrome $(10,11)$. Notably, small intestinal dysmotility is considered to be a common complication following several brain events, including traumatic brain injury (TBI) (11-13) and ischemic stroke (14). ICH is a serious brain disease, the pathophysiological common features of which are in accordance with the other brain events mentioned above. However, to date, no study has investigated the complication of SIM following ICH. The 
present study hypothesized that ICH may also induce significant small intestinal dysmotility as occurs in ischemic stroke and TBI. This is important in relation to the period of growth and development of anatomy and biomechanics in children, as small intestinal dysmotility not only affects the prognosis of the disease itself, but may also affect the future growth, nutritional status and mental development of the child.

Ghrelin is a 28 -amino acid peptide, which is primarily secreted from the stomach, and is distributed in the gastrointestinal (GI) tract and the central nervous system $(15,16)$. Ghrelin has also been found in other tissues, including the pancreas, lungs, kidney, ovaries, gonads, adrenal glands, myocardium, adipose tissue and placenta of humans and rodents (17-20). In various pathological and physiological conditions, ghrelin is secreted into the circulatory system. Ghrelin has several physiological functions, including stimulating food intake (21), modulating systemic metabolism (16), regulating the secretion of gastric acid (22), affecting sleep (23), inducing cell proliferation (24) and reducing the thermogenesis of brown adipose tissue (25). There has been increasing interest regarding its potent effects on gastric emptying and GI motility. A number of studies have shown that the peptide is vital in protecting against GI dysmotility in various diseases, including multiple system atrophy (26), systemic sclerosis (27), stress (28), shock (29), diabetes (30) and brain events (11-14). However, the protective role and underlying mechanisms of ghrelin in ICH-induced small intestinal dysmotility remain to be elucidated, which has limited systemic treatment paradigms for pediatric ICH.

In the present study, the primary aim was to determine the association between serum levels of ghrelin and SIM disorder post-ICH in mice. The second objective was to evaluate the potential effect of exogenous ghrelin administration on ICH-induced SIM disorder. It was shown that ghrelin administration enhanced SIM by downregulating the expression of inducible nitric oxide synthase (iNOS)/nitric oxide (NO) via the cholinergic pathway following pediatric $\mathrm{ICH}$ in mice.

\section{Materials and methods}

Animals. Male C57BL/6 mice (4-6 weeks old) were purchased from the Experimental Animal Center of the Chinese Academy of Sciences (Shanghai, China). All animal protocols were approved by the Laboratory Animal Ethics Committee of the First People's Hospital of Nantong (Nantong, China; no. SYYLS2016009). Animal experiments were performed in accordance with the rules of the US National Institutes of Health Guidelines (31). All mice were housed at a constant temperature $\left(18-22^{\circ} \mathrm{C}\right)$ and humidity in a $12 \mathrm{~h}$ light/dark cycle under specific pathogen-free conditions. Sterilized food and water were provided ad libitum. All efforts were made to minimize suffering and to reduce the number of mice included.

ICH model. The animal model was induced by injecting autologous blood in two stages, in a stereotactic manner, as described previously with minor modifications (32). The mice were anesthetized with a single intraperitoneal injection of ketamine $(100 \mathrm{mg} / \mathrm{kg}$ ) and xylazine $(10 \mathrm{mg} / \mathrm{kg})$ (Sigma, Merck Millipore, Darmstadt, Germany). The mice were placed in a stereotactic frame (RWD Life Science, Shenzhen, China) and subjected to ICH via autologous blood infusion. A $1 \mathrm{~mm}$ burr hole was drilled $2.3 \mathrm{~mm}$ lateral to the midline and $0.2 \mathrm{~mm}$ anterior to the bregma. The autologous blood $(25 \mu \mathrm{l})$ was collected using a Hamilton syringe from a tail cut. A needle was advanced $3.0 \mathrm{~mm}$ into the right striatum. The autologous blood $(25 \mu \mathrm{l})$ was then injected using a microinfusion pump (World Precision Instruments, Sarasota, FL, USA) via a double injection technique. An initial volume of $5 \mu \mathrm{l}$ was injected at a rate of $1.5 \mu \mathrm{l} / \mathrm{min}$. Following a $10 \mathrm{~min}$ injection-free interval, the remaining autologous blood $(20 \mu \mathrm{l})$ was delivered at the same rate. To minimize blood backflow, the needle was left in place for another $10 \mathrm{~min}$. Following withdrawal of the needle, the scalp was sutured. Sham control rats had the needle inserted only. Following surgery, the animals were returned back into their cage.

Drugs and chemicals. Ghrelin (Tocris Bioscience, Ellisville, MI, USA) was dissolved in physiological saline and injected intraperitoneally at a dose of 50,100 or $200 \mu \mathrm{g} / \mathrm{kg}$ prior to charcoal meal induction. Atropine $(1 \mathrm{mg} / \mathrm{kg})$, phentolamine (30 mg/kg), propranolol (20 mg/kg), all from The Seventh Pharmaceutical Co, Ltd. (Wuxi, China), L-NAME (50 mg/kg) and L-arginine (300 mg/kg), from Sigma-Aldrich; Merck Millipore, were freshly prepared in $0.9 \%$ saline on the day of the experiment and pretreated intraperitoneally together with ghrelin.

Three experiments were performed to determine the association between serum levels of ghrelin and SIM, the effect of the exogenous ghrelin administration on SIM disorder, and its underlying mechanisms post-ICH. In the first experiment, the animals were randomly divided into six groups ( $n=6 /$ group): Sham group and $\mathrm{ICH}$ groups at 3 , $6,12,24$, and $72 \mathrm{~h}$. In the second experiment, the animals were randomly divided into seven groups (n=9/group): Sham; $\mathrm{ICH} ; \mathrm{ICH}+$ ghrelin $(50 \mu \mathrm{g} / \mathrm{kg}) ; \mathrm{ICH}+\operatorname{ghrelin}(100 \mu \mathrm{g} / \mathrm{kg})$; $\mathrm{ICH}+$ ghrelin $(200 \mu \mathrm{g} / \mathrm{kg})$; ICH+ghrelin + L-NAME; and $\mathrm{ICH}+$ ghrelin $+\mathrm{L}$-arginine. In the third experiment, the animals were divided into four groups ( $\mathrm{n}=6 /$ group): $\mathrm{ICH}+$ ghrelin; $\mathrm{ICH}+$ ghrelin + atropine; $\mathrm{ICH}+$ ghrelin + phentolamine; and $\mathrm{ICH}+$ ghrelin + propranolol.

Neurobehavioral deficits. Neurobehavioral deficits in the mice were examined by investigators in a blinded-manner. The Rotarod test was performed to evaluate motor coordination. Prior to ICH induction, the mice were trained three times per day for 3 days; each trial lasted for 5 min with a $2 \mathrm{~h}$ interval between each trial at a slow speed of $4 \mathrm{rpm}$. The speed was gradually increased to $40 \mathrm{rpm}$ when the animals were habituated. Following ICH induction, the animals were tested three times per day on days $1,3,5$ and 7 , and the average latency to falling was recorded.

The forelimb placement test was performed to evaluate the reflexive motor ability of the contralateral forelimb. The investigator stimulated the respective vibrissae to elicit excitation once per trial for 10 trials. The percentages of successful left paw placing responses were determined for the impaired forelimb.

For the corner turn test, the animals were allowed to advance into a $30^{\circ}$ corner and turn either left or right to exit. The test was repeated 10-15 times, and the percentage of 
turning direction was calculated as follows: Number of left turns/total turns x100.

Histopathology. Segments of ileum were harvested from the mice in each group $(3 \mathrm{~h}, 12 \mathrm{~h}$ and 3 days in the sham surgery and post-ICH groups) and fixed in $10 \%$ neutral formalin for $24 \mathrm{~h}$. The samples were embedded in paraffin and cut into $4 \mu \mathrm{m}$ sections, which were then mounted on glass slides. The sections were stained with hematoxylin and eosin (H\&E). The histopathological changes in the samples were observed in a blinded-manner using an inverted microscope (Leica Microsystems GmbH, Wetzlar, Germany).

Enzyme-linked immunosorbent assay (ELISA). The serum levels of ghrelin and NO were quantified at each time point using an ELISA kit (R\&D systems, Minneapolis, MN, USA) according to the manufacturer's protocol. The absorbance at $450 \mathrm{~nm}$ was recorded and a standard curve was established to calculate the protein concentration.

SIM. The mice were fasted for $24 \mathrm{~h}$ prior to the experiment. A $0.1 \mathrm{ml}$ volume of charcoal meal $(5 \%$ activated charcoal suspended in $10 \%$ aqueous gum arabic) was injected into the stomach of each mouse via a gastric tube. After $30 \mathrm{~min}$, the mice were sacrificed at each time point. Following laparotomy, the entire small intestine was harvested. The distance traveled by the charcoal of from the pylorus to the furthest point was recorded. The ratio of small intestine impelling force was measured using the following formula: Ratio of intestinal impelling force $(\%)=$ distance traveled by the charcoal/total length of the small intestine $\mathrm{x} 100$.

Reverse transcription-quantitative polymerase chain reaction (RT-qPCR) analysis. Total RNA from the tissues of the small intestine was extracted using TRIzol reagent (Invitrogen, Watltham, MA, USA) according to the manufacturer's protocol. Spectrophotometric analysis $\left(\mathrm{OD}_{260 / 280}\right)$ was used to determine the quantity of RNA. Reverse transcription of the RNA into cDNA was performed using a Prime Script RT reagent kit (Takara, Otsu, Japan). Primers (Table I), which were synthesized commercially by Sangon Biotech Co. Ltd. (Shanghai, China), were designed to amplify the target genes. RT-qPCR was performed according to the manufacturer's protocol using an ABI 7500 PCR instrument with SYBR Green (Takara Bio, Inc.). Briefly, the reactions were performed using $1 \mu \mathrm{l} \mathrm{cDNA}$, $0.4 \mu \mathrm{l}$ PCR forward primer, and $0.4 \mu \mathrm{l}$ reverse primer in a $10 \mu \mathrm{l}$ total reaction volume. Cycling condition were as follows: An initial predenaturation step at $95^{\circ} \mathrm{C}$ for $30 \mathrm{sec}$, followed by 40 cycles of denaturation at $95^{\circ} \mathrm{C}$ for $5 \mathrm{sec}$ and annealing at $60^{\circ} \mathrm{C}$ for $30 \mathrm{sec}$ (33). Data were determined using the $2^{-\Delta \Delta \mathrm{Cq}}(34)$ method with SDS software version 2.4.1 (Applied Biosystems, Thermo Fisher Scientific, Inc.) and $\beta$-actin was quantified as an endogenous control.

Western blot analysis. Total protein from the small intestine tissues was extracted with a mixture of RIPA buffer (EMD Millipore, Bedford, MA, USA). Following centrifugation at $12,000 \mathrm{x} \mathrm{g}$ for $10 \mathrm{~min}$ at $4^{\circ} \mathrm{C}$, the supernatant was collected. Protein concentrations were measured using a bicinchoninic acid assay (Thermo Fisher Scientific, Inc.). The samples were diluted in protein loading buffer (Sunshine Biotechnology, Nanjing, China) and boiled for $5 \mathrm{~min}$ at $95^{\circ} \mathrm{C}$. Subsequently, $30 \mu \mathrm{g}$ total protein was separated on a $10 \%$ sodium dodecyl sulfate-polyacrylamide gel by electrophoresis. The proteins were then electrotransferred onto a $0.45 \mu \mathrm{m}$ PVDF membrane (EMD Millipore). The membranes were blocked for $1 \mathrm{~h}$ in 5\% skim milk and probed with primary antibodies from Abcam (Cambridge, UK) at the following dilutions: iNOS (1:50 dilution, catalog no. ab3523), nNOS (1:2,000 dilution, catalog no. ab76067), eNOS (1:1,000 dilution, catalog no. ab95254), and $\beta$-actin (1:10,000 dilution, catalog no. ab3280) at $4^{\circ} \mathrm{C}$ overnight, respectively. The blots were then incubated with goat anti-rabbit (catalog no. HA1001-100) or goat anti-mouse (catalog no. HA1006) HRP-conjugated secondary antibody (1:5,000 dilution; HuaAn Biotechnology, Hangzhou, Zhejiang, China) for $1 \mathrm{~h}$ at room temperature. The immunoreactive bands were detected using ECL chemiluminescence reagent (Pierce, Rockford, IL, USA) and quantified using Quantity One software version 4.6.2 (Bio-Rad, Hercules, CA, USA).

Statistical analysis. The statistical analysis was performed using SPSS 16.0 (SPSS, Chicago, IL, USA). Differences between groups were analyzed using one-way analysis of variance followed by Student-Newman-Keuls test. Correlation was assessed using Pearson's correlation coefficient. Quantitative data are expressed as the mean \pm standard deviation. $\mathrm{P}<0.05$ was considered to indicate a statistically significant difference.

\section{Results}

Changes in neurological behavior. To evaluate establishment of the ICH model induced by intracerebral infusion of autologous blood, neurological behavior was observed and recorded. No neurobehavioral deficits were observed in the sham group, whereas the mice subjected to intracerebral blood infusion had significant neuroethological abnormalities within 7 days following surgery. As shown in Fig. 1A, a significant reduction in retention time on the Rotarod was detected on days 1-7 post-ICH. Following ICH, the retention times on the Rotarod decreased by $\sim 50.92,57.03,49.82$ and $47.59 \%$ on days $1,3,5$ and 7 , respectively (all $\mathrm{P}<0.01$ ). In the forelimb-placing test, the blood-infused mice presented with marked forelimb placing deficits, compared with the sham mice, at each time point (Fig. 1B). Following ICH, the forelimb-placing score was decreased by $\sim 73.61,78.49,75.00$ and $69.56 \%$ on days 1,3 , 5 and 7 , respectively (all $\mathrm{P}<0.01$ ). Compared with the sham controls, the corner turn deficits were significantly higher on days $1,3,5$, and 7 post-ICH (Fig. 1C). The corner turn score was increased by $\sim 60.60,64.45,54.30$ and $48.68 \%$ on days 1,3 , 5 and 7 (all $\mathrm{P}<0.01$ ) post-ICH. Together, these results indicated that the ICH model using the intracerebral autologous blood infusion were established successfully, and the experimental ICH model was suitable for use in the subsequent experiments aimed for determining the role of ghrelin on SIM disorder post-ICH in vivo.

Changes in intestinal mucosa tissues. To determine the intestinal mucosal injury post-ICH, sections of ileum from sham group and $\mathrm{ICH}$ groups at 3, 12 and $72 \mathrm{~h}$ were stained using 
Table I. Polymerase chain reaction primer sequences.

\begin{tabular}{lll}
\hline Target gene & \multicolumn{1}{c}{ Sense primer $\left(5^{\prime}-3^{\prime}\right)$} & \multicolumn{1}{c}{ Antisense primer $\left(5^{\prime}-3^{\prime}\right)$} \\
\hline iNOS & CCTCCTCCACCCTACCAAGT & CACCCAAAGTGCTTCAGTCA \\
nNOS & GCTTCAGGAATATGAGGAATGG & TGATGGAATAGTAGCGAGGTTGT \\
eNOS & TGTCTGCGGCGATGTCACT & CATGCCGCCCTCTGTTG \\
-actin & GTGACGTTGACATCCGTAAAGA & GCCGGACTCATCGTACTCC
\end{tabular}

iNOS, inducible nitric oxide synthase; nNOS, neuronal nitric oxide synthase; eNOS, endothelial nitric oxide synthase.

A

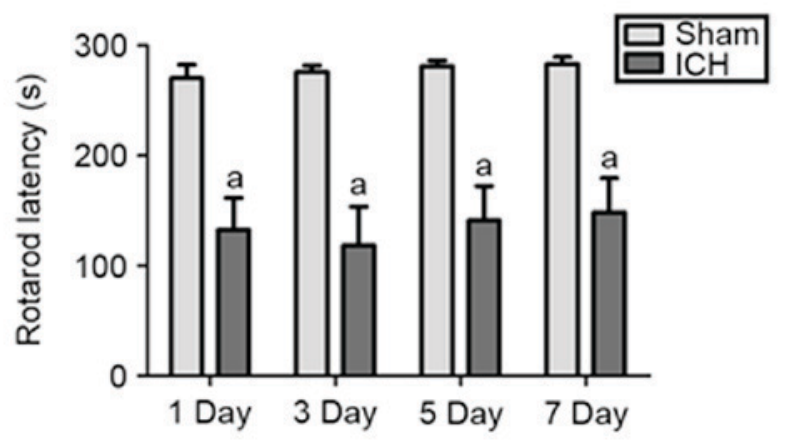

B

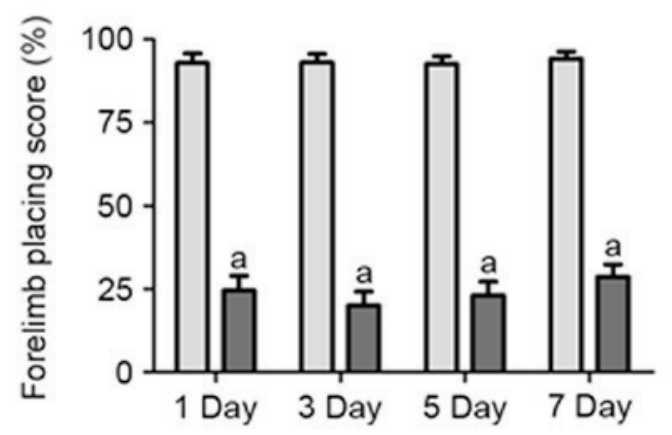

C

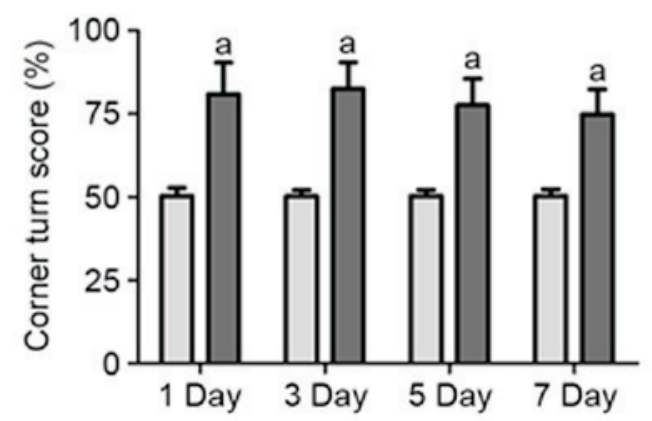

Figure 1. Evaluation of neurological deficits following ICH. (A) Rotarod, (B) forelimb-placing and (C) corner turn tests were performed at 1,3,5 and 7 days post-ICH (infusion of $25 \mu 1$ autologous blood into the right striatum) and in the sham control. Values are presented as the mean \pm standard deviation ( $\mathrm{n}=9 /$ group), ${ }^{\mathrm{a}} \mathrm{P}<0.01$, vs. sham group. $\mathrm{ICH}$, intracerebral hemorrhage.

H\&E staining. Visually, the sections showed approximately intact mucosa in the sham group (Fig. 2A). By contrast, mucosal damage occurred as early as $3 \mathrm{~h}$ post-ICH, shown as mild lifting of epithelial cells from the top of villi, and shortened and thickened villi (Fig. 2B). In addition, severe lifting of epithelial cells, epithelial disorganization, fusion of adjacent villi, inflammatory cell infiltration, and naked lamina propria were observed at $12 \mathrm{~h}$ (Fig. 2C) and the changes were maximal at $72 \mathrm{~h}$ (Fig. 2D).

Correlations between serum levels of ghrelin and SIM. To determine the changes in serum levels of ghrelin following ICH, ELISA was performed. As shown in Fig. 3A, the serum levels of ghrelin were significantly elevated between 3 and $72 \mathrm{~h}$ post-ICH $(6.60 \pm 0.81,6.99 \pm 0.77,8.63 \pm 0.92,8.00 \pm 0.74$ and $6.68 \pm 0.72 \mathrm{ng} / \mathrm{ml}$ post- $-\mathrm{ICH}$, vs. $5.48 \pm 0.77 \mathrm{ng} / \mathrm{ml}$ in the sham group, respectively; $\mathrm{P}<0.05$ ). The serum level of ghrelin increased as early as $3 \mathrm{~h}$, peaked at $12 \mathrm{~h}$, and remained at a significantly higher level until $72 \mathrm{~h}$.

To examine the changes in SIM post-ICH, charcoal meal staining was performed at each time point. Compared with the sham controls, SIM was decreased between 3 and $72 \mathrm{~h}$ post-ICH $(56.82 \pm 2.51,42.80 \pm 3.93,34.61 \pm 4.10,38.64 \pm 2.01$ and $45.63 \pm 3.64 \%$, vs. $75.83 \pm 2.46 \%$ in the sham group, respectively; Fig. $3 \mathrm{~B} ; \mathrm{P}<0.01)$. Consistently, small intestine dysmotility peaked at $12 \mathrm{~h}$ post-ICH. Based on these results, exogenous ghrelin was administered for $12 \mathrm{~h}$ following ICH for the subsequent experiments aimed at determining the effect of ghrelin on SIM.

The correlations between serum levels of ghrelin and SIM were analyzed using Pearson's correlation coefficients. There was a significant negative correlation between the serum level of ghrelin and SIM ( $r=-0.783 ; \mathrm{P}<0.01$; Fig. 3C).

Effect of ghrelin on SIM. To investigate the effect of ghrelin on SIM in vivo, the ratio of small intestinal impelling force was measured at $12 \mathrm{~h}$ post-ICH. As shown in Fig. 4, SIM was significantly increased in a dose-dependent manner by a single injection of ghrelin of 50, 100 and $200 \mu \mathrm{g} / \mathrm{kg}(49.95 \pm 3.27$, $57.11 \pm 5.61$ and $61.11 \pm 5.84 \%$, vs. $34.61 \pm 4.10 \%$ in the vehicle, respectively) following the induction of ICH $(\mathrm{P}<0.01)$. However, no significant difference was found between $200 \mu \mathrm{g} / \mathrm{kg}$ ghrelin treatment and $100 \mu \mathrm{g} / \mathrm{kg}$ ghrelin treatment ( $\mathrm{P}>0.05)$. Therefore, a dose of $100 \mu \mathrm{g} / \mathrm{kg}$ ghrelin was used for administration in the subsequent experiments to determine its underlying mechanisms.

Effect of ghrelin on the iNOS/NO pathway. To determine the NO levels following ghrelin administration, ELISA was performed. Compared with the sham group, the vehicle-treated 
A

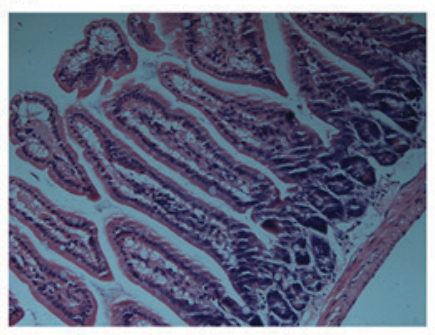

B

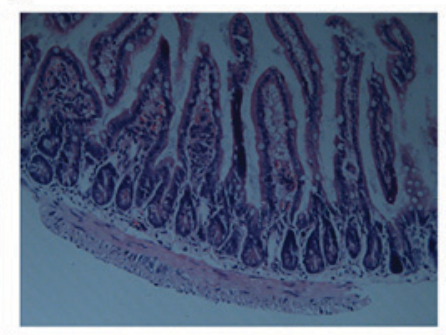

C

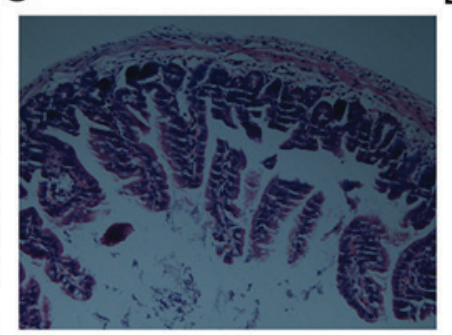

D

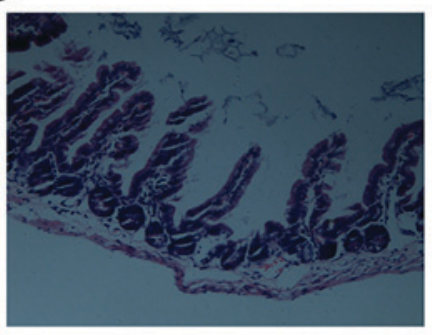

Figure 2. Pathobiology of intestinal mucosa stained using hematoxylin and eosin. (A) Intestinal mucosal structure in the sham group was almost intact. (B) Mild villi damage was shown at $3 \mathrm{~h}$ in the ICH groups. (C) Severe lifting of epithelial cells, epithelial disorganization, fusion of adjacent villi, inflammatory cell infiltration, and naked lamina propria were observed at $12 \mathrm{~h}$, and (D) gradually worsened on day 3 . $\mathrm{n}=3 / \mathrm{group}$. ICH, intracerebral hemorrhage.

A

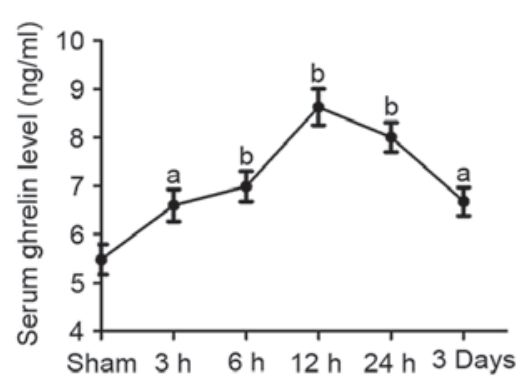

B

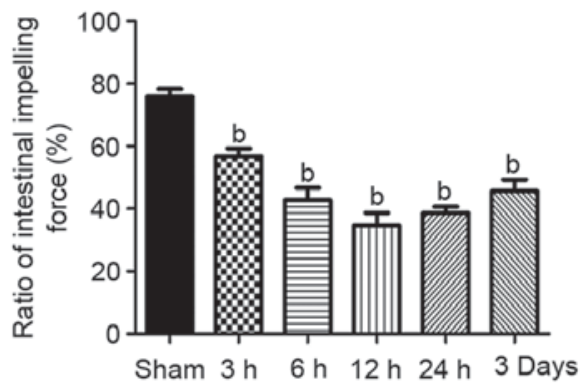

C

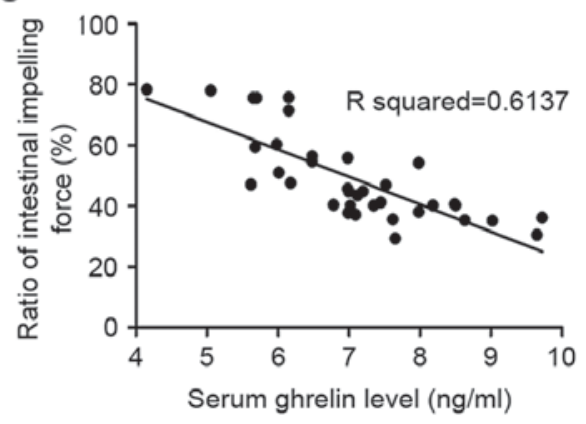

Figure 3. Association between serum levels of ghrelin and SIM in the mice ICH model. (A) Serum levels of ghrelin and (B) SIM at 3, 6, 12, 24 h and 3 days post-ICH (infusion of $25 \mu \mathrm{l}$ autologous blood into the right striatum) or sham control. (C) A significant negative correlation was shown between serum level of ghrelin and SIM in the ICH model ( $\mathrm{r}=-0.783 ; \mathrm{P}<0.01)$. Values are presented as the mean \pm standard deviation $(\mathrm{n}=6 / \mathrm{group})$. ${ }^{\text {a }} \mathrm{P}<0.05$ and ${ }^{\mathrm{b}} \mathrm{P}<0.01, \mathrm{vs}$. sham group. ICH, intracerebral hemorrhage; SIM, small intestinal motility.

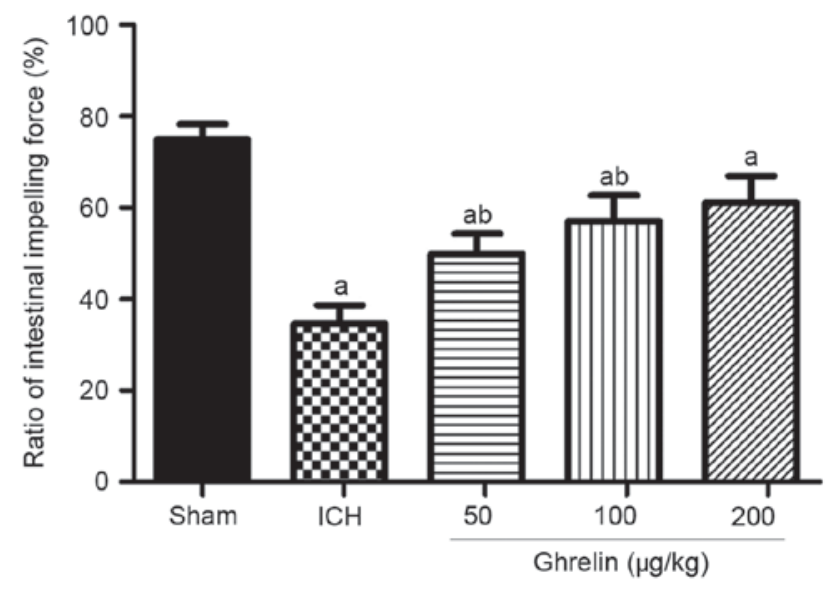

Figure 4. Ghrelin increases small intestinal motility following ICH at $12 \mathrm{~h}$. Ratio of intestinal impelling force was recorded following injection with different doses of ghrelin $(50,100$ and $200 \mu \mathrm{g} / \mathrm{kg})$. Values are presented as the mean \pm standard deviation $(n=6)$. ${ }^{a} \mathrm{P}<0.01$, vs. sham group; ${ }^{b} \mathrm{P}<0.05$, vs. former group. ICH, intracerebral hemorrhage.

group exhibited higher NO levels at $12 \mathrm{~h}$ post-ICH (52.19 \pm 5.25 , vs. $99.59 \pm 6.84 \mu \mathrm{mol} / 1$; $\mathrm{P}<0.01)$. However, ghrelin administration markedly reduced the $\mathrm{ICH}$-induced levels of $\mathrm{NO}$ (78.79 \pm 6.51 , vs. 99.59 $\pm 6.84 \mu \mathrm{mol} / 1$; $\mathrm{P}<0.01$; Fig. 5A).

To further determine whether the ghrelin-induced reduction of NO was NOS-dependent or not, the expression levels of iNOS, nNOS and eNOS were examined using RT-qPCR and western blot analyses. At the mRNA level, the expression levels of iNOS, nNOS and eNOS were significantly increased in the vehicle-treated ICH group, compared with those in the sham group $(2.62 \pm 0.26$, vs. $0.41 \pm 0.17 ; 1.06 \pm 0.13$, vs. $0.21 \pm 0.10$; and $2.28 \pm 0.25$, vs. $0.72 \pm 0.13$, respectively; $\mathrm{P}<0.01$; Fig. 5B). Ghrelin (100 mg/kg) significantly reduced the mRNA expression of iNOS, compared with the ICH group $(1.71 \pm 0.37$, vs. 2.62 $\pm 0.26 ; \mathrm{P}<0.01)$; however, it did not significantly alter the mRNA expression of nNOS $(0.92 \pm 0.17$, vs. $1.06 \pm 0.13$; $\mathrm{P}>0.05)$ or eNOS $(2.67 \pm 0.36$, vs. $2.28 \pm 0.25 ; \mathrm{P}>0.05)$. At the protein level, a similar effect was observed (Fig. 5C). Compared with the sham group, ICH induced a significant increase in the protein expression levels of iNOS, nNOS and eNOS $(1.90 \pm 0.21$, vs. $1.00 \pm 0.17 ; 1.50 \pm 0.16$, vs. $1.00 \pm 0.16$; and $1.83 \pm 0.21$, vs. $1.00 \pm 0.15$, respectively; $\mathrm{P}<0.01)$. Similarly, compared with the ICH group, the protein expression of iNOS $(1.41 \pm 0.22$, vs. $1.90 \pm 0.21 ; \mathrm{P}<0.01)$, but not of nNOS $(1.34 \pm 0.16$, vs. $1.50 \pm 0.16 ; \mathrm{P}>0.05)$ or $\operatorname{eNOS}(1.92 \pm 0.16$, vs. $1.83 \pm 0.21$; $\mathrm{P}>0.05)$, was downregulated by ghrelin administration.

To further confirm the protective effect of ghrelin on SIM via the iNOS/NO pathway, L-NAME and L-argnine were used. As shown in Fig. 6, co-treatment with L-NAME, a nonselective NOS inhibitor, markedly enhanced SIM, compared with treatment with ghrelin alone at $12 \mathrm{~h}$ post-ICH $(67.99 \pm 5.09$, vs. $57.11 \pm 5.61 \%$; $\mathrm{P}<0.01)$. By contrast, co-treatment with L-argnine, a precursor of NOS, weakened SIM in comparison with ghrelin treatment alone at $12 \mathrm{~h}$ post-ICH $(44.86 \pm 6.11$, vs. 57.11 $\pm 5.61 \%$; $\mathrm{P}<0.01)$. 
A
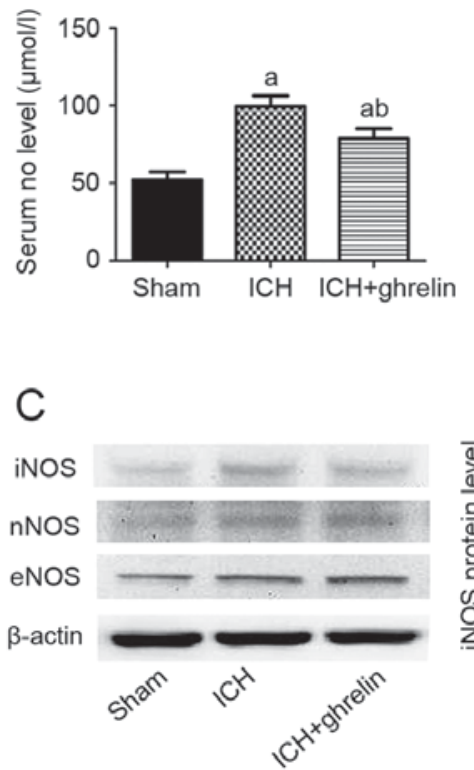

B
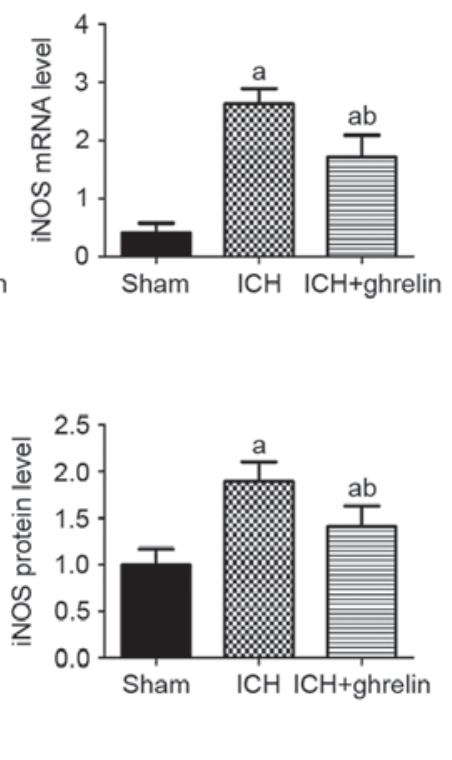
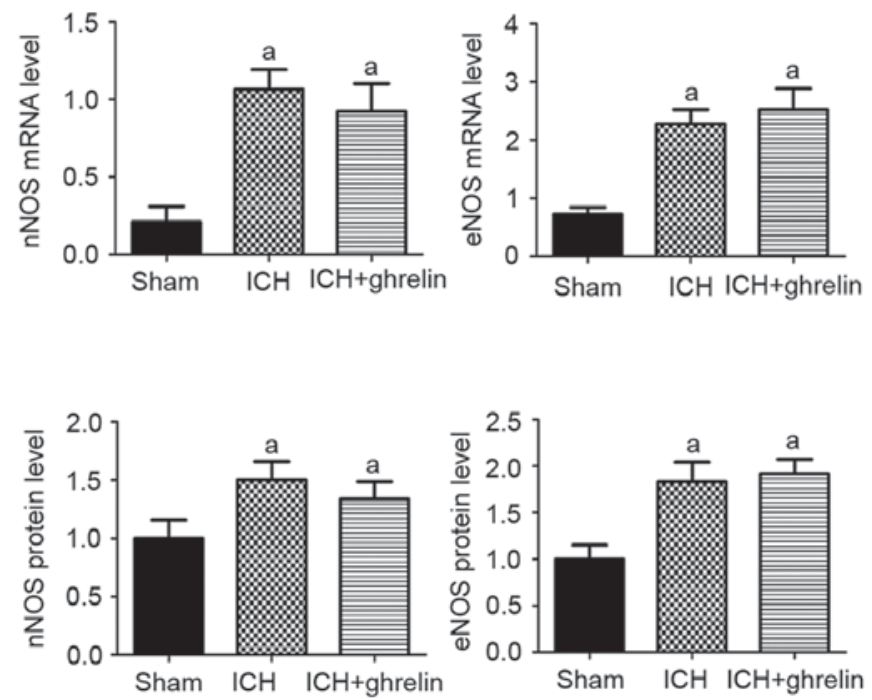

Figure 5. Effect of ghrelin on the expression of NOS/NO. (A) Serum levels of NO were determined at $12 \mathrm{~h}$ in the sham, ICH, and ICH + ghrelin groups. (B) Reverse transcription-quantitative polymerase chain reaction and (C) western blot analyses were performed to detect the mRNA and protein expression levels of the three isoforms of NOS (iNOS, nNOS and eNOS) in the sham group and ICH groups $+/$-ghrelin at $12 \mathrm{~h}$, respectively. Values are presented as the mean \pm standard deviation $(n=6)$. a $\mathrm{P}<0.01$, vs. sham group; ${ }^{b} \mathrm{P}<0.05$, vs. former group. Data are representative of three independent experiments. ICH, intracerebral hemorrhage; NO, nitric oxide; iNOS, inducible nitric oxide synthase; nNOS, neuronal nitric oxide synthase; eNOS, endothelial nitric oxide synthase.

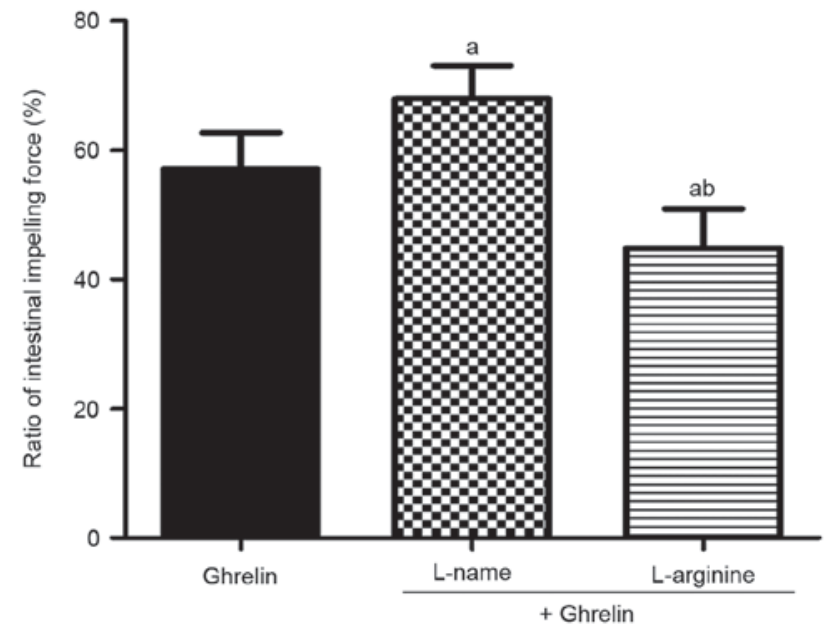

Figure 6. Effect of ghrelin on small intestinal motility via the NOS-dependent pathway. Ratio of intestinal impelling force was evaluated by administration of ghrelin following pretreatment with L-NAME and L-arginine, respectively. Values are presented as the mean \pm standard deviation $(\mathrm{n}=6) .{ }^{\mathrm{a}} \mathrm{P}<0.01$, vs. sham group; ${ }^{\mathrm{b}} \mathrm{P}<0.01$, vs. former group. L-NAME, $N_{\omega}$-nitro-L-arginine methyl ester hydrochloride.

Effect of ghrelin on SIM via the cholinergic excitatory pathway. To further determine whether the ghrelin-mediated reduction of iNOS/NO was cholinergic pathway-dependent or not, M-cholinergic and adrenergic receptor antagonists were administered. As shown in Fig. 7, atropine, an antagonist of M-cholinergic receptor, significantly reversed the effect of ghrelin on SIM $(40.61 \pm 4.9$, vs. $57.11 \pm 5.61 \%$; $\mathrm{P}<0.01)$. By contrast, no significant inhibitory effects were observed on the excitatory effect of ghrelin by the adrenergic receptor

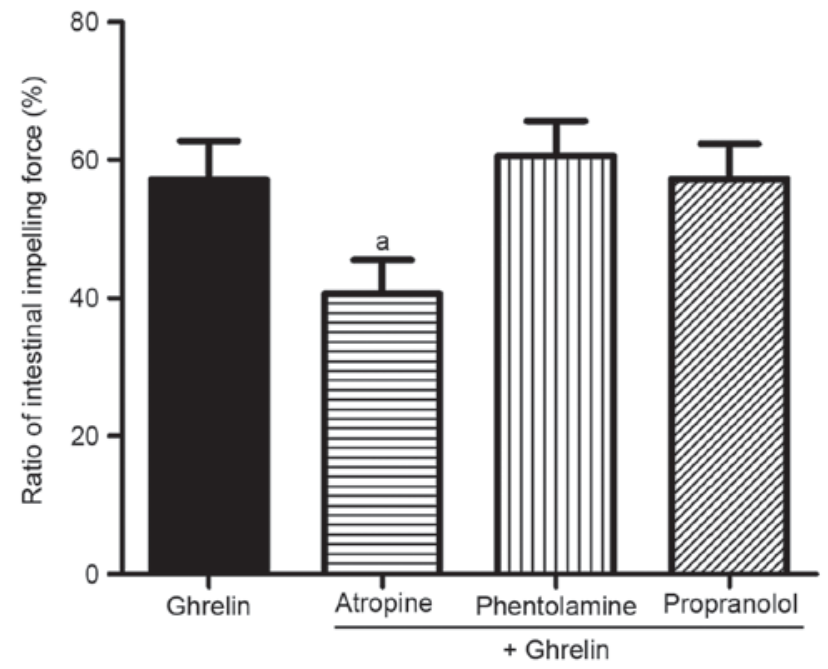

Figure 7. Effect of ghrelin on small intestinal motility via the cholinergic excitatory pathway. Ratio of intestinal impelling force was measured by administration of ghrelin following pretreatment with atropine, phentolamine and propranolol, respectively. Values are presented as the mean \pm standard deviation $(n=6)$. ${ }^{\text {a }}<00.01$, vs. sham group.

antagonists phentolamine or propranolol (60.61 \pm 4.95 , vs. 57.11 \pm 5.61 and $57.28 \pm 5.03$, vs. $57.11 \pm 5.61 \%$, respectively; $\mathrm{P}>0.05)$, compared with the control group.

\section{Discussion}

SIM disorder is a common complication following pediatric $\mathrm{ICH}$. However, it has not been investigated extensively and the pathophysiological changes have not been discussed or 
evaluated extensively in the past. Of note, small intestinal dysmotility may not only affect the prognosis of pediatric $\mathrm{ICH}$ itself, but it may affect the child's future mental and physical development. In the present study, the primary findings were as follows: i) Neurological dysfunction was observed in mice administered with an intracerebral infusion of autologous blood; ii) temporal profiles of intestinal mucosal damage and SIM disorder were induced by ICH in mice; iii) evaluation of the time-course showed that the serum levels of ghrelin increased markedly between $3 \mathrm{~h}$ and 3 days, peaked at $12 \mathrm{~h}$, and showed a significant negative correlation with SIM; iv) administration of ghrelin effectively attenuated ICH-induced small intestinal dysmotility in a dose-dependent manner; v) ghrelin administration appeared to ameliorate ICH-induced small intestinal dysmotility by reducing iNOS/NO via the cholinergic excitatory pathway. To the best of our knowledge, the present study is the first in vivo investigation to show the association between ghrelin and SIM following experimental ICH, further clarifying the effect of ghrelin on SIM disorder.

It is important to note that intestinal mucosal damage may progress to ulcer formation and upper GI bleeding according to severity. Clinically, the frequency of upper GI bleeding following ICH is almost $30 \%(35,36)$, which leads to long-term hospitalization and higher mortality rates. In the present study, severe damage of the intestinal mucosa occurred rapidly as early as $3 \mathrm{~h}$ following ICH and persisted for 3 days. These findings agree with the results of other brain event models $(11,14,37)$, including TBI and ischemic stroke. This suggests that ICH induces intestinal mucosal damage, which may develop into upper GI bleeding without reasonable intervention. In addition, previous evidence has revealed that the mucosal damage leads to GI dysmotility, and vice versa $(11,14)$.

As is already known, the brain-gut axis and brain-gut peptides are important in regulating GI motility. Primary and secondary brain injuries lead to changes in the synthesis and secretion of brain-gut peptides, which are involved in altering small intestine motility. To date, multiple brain-gut peptides have been identified (38-42), including somatostatin, gastri), cholecystokinin, vasoactive intestinal peptide, motilin, substance $\mathrm{P}$ and ghrelin. Ghrelin is an endogenous ligand of the growth hormone secretagogue receptor, and has been shown to be important in several diseases (26-30). However, the dynamic changes in serum levels of ghrelin during the early stages of $\mathrm{ICH}$, and its time-dependent correlation with SIM, have not been reported previously. In the present study, the levels of ghrelin increased in a time-dependent manner in the serum of ICH mice. By contrast, SIM showed ab opposite trend between $3 \mathrm{~h}$ and 3 days post-ICH. At $12 \mathrm{~h}$, the changes in serum levels of ghrelin and SIM peaked following ICH. The present study also demonstrated a negative correlation between the serum level of ghrelin and SIM. These data are in agreement with the findings of another previous study, which demonstrated the association in an ischemic stroke model (14). Therefore, the serum level of ghrelin may serve as a potential hallmark for predicting ICH-induced SIM disorder in clinical application. However, the cause-and-effect association between serum levels of ghrelin and SIM disorder remains to be elucidated. In another study, Xu et al (14) offered a potential explanation for this association in a middle cerebral artery occlusion model. Their results showed that the brain event caused neurohumoral regulation disorders, leading to gastrointestinal motility disorder. The concomitant effect caused the decrease in SIM, whereas the increase in the serum level of ghrelin was compensatory. Therefore, the negative correlation between the serum level of ghrelin and intestinal motility can be explained as a compensatory reaction. The adaptive upregulation of serum levels of ghrelin may lead to ICH-induced intestinal hypomotility to restore GI kinetic energy. The decrease in intestinal kinetics demonstrates that the compensation cannot sustain the physiological small intestinal function. To determine the effect of ghrelin on ICH-induced SIM disorder in the present study, exogenous ghrelin was administrated. Notably, exogenous ghrelin administration significantly attenuated small intestine hypomotility in a dose-dependent manner following ICH. Taken together, these results indicated that the induction of endogenous ghrelin serves as an adaptive self-defense mechanism, although it is insufficient to completely attenuate the small intestinal hypomotility caused by ICH. Ghrelin offers a potential novel approach to alleviate SIM disorder following ICH.

NOS neurons are well-known inhibitory cells to GI motility, which are distributed extensively in the submucosal and myenteric nerve networks $(29,43)$. NOS has three isoforms (iNOS, nNOS and eNOS) and can synthesize NO, which inhibits GI motility. In the present study, three lines of evidence demonstrated the effect of ghrelin on SIM disorder via the iNOS/NO inhibitory pathway. Firstly, experiments revealed that the ICH-induced serum expression of NO was significantly inhibited by ghrelin administration, which was consistent with the findings of a lipopolysaccharide-induced GI motility disturbance model (29). However, the results from a series of rodent models $(29,44,45)$ showed that ghrelin administration downregulated the expression of NOS/NO. The present study found that ghrelin administration markedly reduced the level of NO by downregulating the expression of iNOS post-ICH, rather than that of nNOS or eNOS, which was determined using RT-qPCR and western blot analysis. These results are in accordance with those of Chen et al (29); ghrelin had no significant effect on the expression of nNOS/NO or eNOS/NO, however, it had a beneficial effect on SIM via inhibiting the expression of iNOS/NO. The present study further confirmed that ghrelin reversed ICH-induced small intestinal hypomotility via the iNOS-dependent pathway by administration with L-NAME or L-argnine. Taken together, these findings demonstrated that ghrelin modulated SIM post-ICH through suppressing the expression of iNOS/NO.

Several studies have demonstrated that NOS/NO decreases GI motility through the autonomic nervous system $(46,47)$. Ghrelin has also been found to be critical in the regulation of gastric emptying via the cholinergic excitatory pathway $(48,49)$. However, whether ghrelin reduces the expression of iNOS/NO via the cholinergic pathway following ICH has not been elucidated previously. In the present study, atropine, phentolamine and propranolol were administered to inhibit the cholinergic, $\alpha$-adrenergic, and $\beta$-adrenergic pathway, respectively. The results suggested that the prokinetic effect of ghrelin was eradicated by atropine, but not by phentolamine or propranolol. These data are in agreement with those previously reported (50). Together, these results suggested that ghrelin attenuated SIM disorder by reducing the expression of NOS/NO via the cholinergic excitatory pathway, but not the $\alpha$ - or $\beta$-adrenergic excitatory pathways. 
In conclusion, the present study is the first, to the best of our knowledge, to investigate the changes in serum levels of ghrelin and SIM following ICH over time. The results provided quantitative evidence suggesting that the administration of ghrelin reversed ICH-induced small intestinal dysmotility by downregulating the expression of iNOS-NO via the cholinergic pathway. Ultimately, based on an improved understanding of ghrelin in ICH-induced intestinal hypomotility, the use of ghrelin as a potential marker for predicting post-ICH kinetic disorders and pharmacological agents may be an effective intervention in clinical application.

\section{Acknowledgements}

This study was supported by the Science and Technology Project Fund (grant no. WQ2014002) from the Health Bureau of Nantong Municipality.

\section{References}

1. Ganesan V, Hogan A, Shack N, Gordon A, Isaacs E and Kirkham FJ: Outcome after ischaemic stroke in childhood. Dev Med Child Neurol 42: 455-461, 2010.

2. Heideman RL, Packer RJ, Albright LA, Freeman CR and Rorke LB: Tumors of the central nervous system.In: Principles and Practice of Pediatric Oncology. Pizzo PA and Poplack DG (eds). Lippincott Williams \& Wilkins, Philadelphia, pp633-697, 1997.

3. Fullerton HJ, Wu YW, Zhao S and Johnston SC: Risk of stroke in children: Ethnic and gender disparities. Neurology 61: 189-194, 2003.

4. Giroud M, Lemesle M, Gouyon JB, Nivelon JL, Milan C and Dumas R: Cerebrovascular disease in children under 16 years of age in the city of Dijon, France: A study of incidence and clinical features from 1985 to 1993. J Clin Epidemiol 48: 1343-1348, 1995.

5. Lynch JK, Hirtz DG, DeVeber G and Nelson KB: Report of the National institute of neurological disorders and stroke workshop on perinatal and childhood stroke. Pediatrics 109: 116-123, 2002.

6. Chung B and Wong V: Pediatric stroke among Hong Kong Chinese subjects. Pediatrics 114: 206-212, 2004.

7. Balami JS and Buchan AM: Complications of intracerebral haemorrhage. Lancet Neurol 11: 101-118, 2012.

8. Lynch JK and Han CJ: Pediatric stroke: What do we know and what do we need to know? Semin Neurol 25: 410-423, 2005.

9. Tack J and Lee KJ: Pathophysiology and treatment of functional dyspepsia. J Clin Gastroenterol 39: 211-216, 2005.

10. Yuan DD, Chi XJ, Jin Y, Li X, Ge M, Gao WL, Guan JQ, Zhang AL and He ZQ: Intestinal injury following liver transplantation was mediated by TLR4/NF- $\kappa \mathrm{B}$ activation-induced cell apoptosis. Mol Med Rep 13: 1525-1532, 2016.

11. Wang YB, Liu J and Yang ZX: Effects of intestinal mucosal blood flow and motility on intestinal mucosa. World J Gastroenterol 17: 657-661, 2011.

12. Keshavarzi Z, Khaksari M and Shahrokhi N: The effects of cyclooxygenase inhibitors on the gastric emptying and small intestine transit in the male rats following traumatic brain injuery. Iran J Basic Med Sci 17: 406-410, 2014.

13. Olsen AB, Hetz RA, Xue H, Aroom KR, Bhattarai D, Johnson E, Bedi S, Cox CS Jr and Uray K: Effects of traumatic brain injury on intestinal contractility. Neurogastroenterol Motil 25: e593-e463, 2013.

14. $\mathrm{Xu} \mathrm{X}, \mathrm{Zhu} \mathrm{Y}$ and Chuai J: Changes in serum ghrelin and small intestinal motility in rats with ischemic stroke. Anat Rec (Hoboken) 295: 307-312, 2012.

15. Gong Y, Xu L, Guo F, Pang M, Shi Z, Gao S and Sun X: Effects of ghrelin on gastric distension sensitive neurons and gastric motility in the lateral septum and arcuate nucleus regulation. J Gastroenterol 49: 219-230, 2014.

16. Cowley MA, Smith RG, Diano S, Tschöp M, Pronchuk N, Grove KL, Strasburger CJ, Bidlingmaier M, Esterman M, Heiman ML, et al: The distribution and mechanism of action of ghrelin in the CNS demonstrates a novel hypothalamic circuit regulating energy homeostasis. Neuron 37: 649-661, 2003.
17. Schellekens H, Dinan TG and Cryan JF: Lean mean fat reducing 'ghrelin' machine: Hypothalamic ghrelin and ghrelin receptors as therapeutic targets in obesity. Neuropharmacology 58: 2-16, 2010.

18. Date Y, Kojima M, Hosoda H, Sawaguchi A, Mondal MS, Suganuma T, Matsukura S, Kangawa $K$ and Nakazato $M$ : Ghrelin, a novel growth hormone-releasing acylated peptide, is synthesized in a distinct endocrine cell type in the gastrointestinal tracts of rats and humans. Endocrinology 141: 4255-4261, 2000.

19. Wang G, Lee HM, Englander E and Greeley GH Jr: Ghrelin-not just another stomach hormone. Regul Pept 105: 75-81, 2002.

20. Gnanapavan S, Kola B, Bustin SA, Morris DG, McGee P, Fairclough P, Bhattacharya S, Carpenter R, Grossman AB and Korbonits M: The tissue distribution of the mRNA of ghrelin and subtypes of its receptor, GHS-R, in humans. J Clin Endocrinol Metab 87: 2988, 2002.

21. Nakazato M, Murakami N, Date Y, Kojima M, Matsuo H, Kangawa $\mathrm{K}$ and Matsukura S: A role for ghrelin in the central regulation of feeding. Nature 409: 194-198, 2001.

22. Peeters TL: Ghrelin and the gut. Endocr Dev 25: 41-48, 2013.

23. Broussard JL, Kilkus JM, Delebecque F, Abraham V, Day A, Whitmore HR and Tasali E: Elevated ghrelin predicts food intake during experimental sleep restriction. Obesity (Silver Spring) 24: 132-138, 2016.

24. Lien GS, Lin CH, Yang YL, Wu MS and Chen BC: Ghrelin induces colon cancer cell proliferation through the GHS-R, Ras, PI3K, Akt, and mTOR signaling pathways. Eur J Pharmacol 776: 124-131, 2016.

25. Lin L, Saha PK, Ma X, Henshaw IO, Shao L, Chang BH, Buras ED, Tong Q, Chan L, McGuinness OP and Sun Y: Ablation of ghrelin receptor reduces adiposity and improves insulin sensitivity during aging by regulating fat metabolism in white and brown adipose tissues. Aging Cell 10: 996-1010, 2011.

26. Ozawa T, Tokunaga J, Arakawa M, Ishikawa A, Takeuchi R, Mezaki N, Miura T, Sakai N, Hokari M, Takeshima A, et al: Abnormal ghrelin secretion contributes to gastrointestinal symptoms in multiple system atrophy patients. J Neurol 260: 2073-2077, 2013.

27. Ariyasu H, Iwakura H, Yukawa N, Murayama T, Yokode M, Tada H, Yoshimura K, Teramukai S, Ito T, Shimizu A, et al: Clinical effects of ghrelin on gastrointestinal involvement in patients with systemic sclerosis. Endocr J 61: 735-742, 2014.

28. Ochi M, Tominaga K, Tanaka F, Tanigawa T, Shiba M, Watanabe T, Fujiwara Y, Oshitani N, Higuchi K and Arakawa T: Effect of chronic stress on gastric emptying and plasma ghrelin levels in rats. Life Sci 82: 862-868, 2008.

29. Chen YT, Tsai SH, Sheu SY and Tsai LH: Ghrelin improves LPS-induced gastrointestinal motility disturbances: Roles of NO and prostaglandin E2. Shock 33: 205-212, 2010.

30. Malin SK, Samat A and Wolski K, Abood B, Pothier CE, Bhatt DL, Nissen S, Brethauer SA, Schauer PR, Kirwan JP and Kashyap SR: Improved acylated ghrelin suppression at 2 years in obese patients with type 2 diabetes: Effects of bariatricsurgery vs. standard medical therapy. Int J Obes 38: 364-370, 2014.

31. Garber J, Barbee RW, Bielitzki J, et al: Guide for the care and use of laboratory animals. 8th edition. Washington DC: National Academies Press, pp1-246, 2011.

32. Rynkowski MA, Kim GH, Komotar RJ, Otten ML, Ducruet AF, Zacharia BE, Kellner CP, Hahn DK, Merkow MB, Garrett MC, et al: A mouse model of intracerebral hemorrhage using autologous blood infusion. Nat Protoc 3: 122-128, 2008.

33. Liu YQ, Tang G, Wang Y, Chen X, Gu X, Zhang Z, Wang Y and Yang GY: Metformin attenuates blood-brain barrier disruption in mice following middle cerebral artery occlusion. J Neuroinflammation 11: 177, 2014.

34. Livak KJ and Schmittgen TD: Analysis of relative gene expression data using real-time quantitative PCR and the 2(-Delta Delta C(T)) method. Methods 25: 402-408, 2001.

35. Misra UK, Kalita J, Pandey S and Mandal SK: Predictors of gastrointestinal bleeding in acute intracerebral haemorrhage. J Neurol Sci 208: 25-29, 2003.

36. Yang TC, Li JG, Shi HM, Yu DM, Shan K, Li LX, Dong XY and Ren TH: Gastrointestinal bleeding after intracerebral hemorrhage: A retrospective review of 808 cases. Am J Med Sci 346: 279-282, 2013.

37. Sun B, Hu C, Fang H, Zhu L, Gao N and Zhu J: The effects of lactobacillus acidophilus on the intestinal smooth muscle contraction through PKC/MLCK/MLC signaling pathway in TBI mouse model. PLoS One 10: e0128214, 2015. 
38. Raybould HE and Taché Y: Cholecystokinin inhibits gastric motility and emptying via a capsaicin-sensitive vagal pathway in rats. Am J Physiol 255: 242-246, 1988.

39. Liu J, Li ZS, Wan XJ and Wang W: Expression and function of apoptosis-related genes $\mathrm{Bcl}-2 / \mathrm{Bax}$ and $\mathrm{Fas} / \mathrm{Fas} \mathrm{L}$ in the course of stress ulcer. Zhonghua Yi Xue Za Zhi 83: 504-509, 2003 (In Chinese).

40. Schmidt WE, Creutzfeldt W, Schleser A, Choudhury AR, Nustede R, Höcker M, Nitsche R, Sostmann H, Rovati LC and Fölsch UR: Role of CCK in regulation of pancreaticobiliary functions and GI motility in humans: Effects of loxiglumide. Am J Physiol 260: G197-G206, 1991.

41. Nguyen NQ, Fraser RJ, Chapman MJ, Bryant LK, Holloway RH, Vozzo R, Wishart J, Feinle-Bisset C and Horowitz M: Feed intolerance in critical illness is associated with increased basal and nutrient-stimulated plasma cholecystokinin concentrations. Crit Care Med 35: 82-88, 2007.

42. Chapman MJ, Nguyen NQ and Deane AM: Gastrointestinal dysmotility: Evidence and clinical management. Curr Opin Clin Nutr Metab Care 16: 209-216, 2013.

43. Bult H, Boeckxstaens GE, Pelckmans PA, Jordaens FH, Van Maercke YM and Herman AG: Nitric oxide as an inhibitory non-adrenergic non-cholinergic neurotransmitter. Nature 345 : 346-347, 1990

44. De Winter BY, Bredenoord AJ, De Man JG, Moreels TG, Herman AG and Pelckmans PA: Effect of inhibition of inducible nitric oxide synthase and guanylyl cyclase on endotoxin-induced delay in gastric emptying and intestinal transit in mice. Shock 18 125-131, 2002.
45. De Winter BY, De Man JG, Seerden TC, Depoortere I, Herman AG, Peeters TL and Pelckmans PA: Effect of ghrelin and growth hormone-releasing peptide 6 on septic ileus in mice. Neurogastroenterol Motil 16: 439-446, 2004.

46. Wang Y, Dong L, Cheng Y and Zhao P: Effects of ghrelin on feeding regulation and interdigestive migrating complex in rats. Scand J Gastroenterol 42: 447-453, 2007.

47. Shuto Y, Shibasaki T, Wada K, Parhar I, Kamegai J, Sugihara H, Oikawa S and Wakabayashi I: Generation of polyclonal antiserum against the growth hormone secretagogue receptor (GHS-R): Evidence that the GHS-R exists in the hypothalamus, pituitary and stomach of rats. Life Sci 68: 991-996, 2001.

48. Greenwood-Van Meerveld B, Krieqsman M and Nelson R Ghrelin as a target for gastrointestinal motility disorders. Peptides 32: 2352-2356, 2011.

49. Ogiso K, Asakawa A, Amitani H and Inui A: Ghrelin: A gut hormonal basis of motility regulation and functional dyspepsia. J Gastroenterol Hepatol 26 (Suppl 3): S67-S72, 2011.

50. Tümer C, Oflazoğlu HD, Obay BD, Kelle M and Taşdemir E: Effect of ghrelin on gastric myoelectric activity and gastric emptying in rats. Regul Pept 146: 26-32, 2008. 